Andrés Biehl y Patricio Velasco (editores), Pedro Morandé. Textos sociológicos escogidos (Santiago: Ediciones UC, 2017).

RESEÑA

\title{
PEDRO MORANDÉ: DEL BARROCO A LOS SISTEMAS SOCIALES
}

\author{
Aldo Mascareño \\ CEP - Universidad Adolfo Ibáñez
}

M ás allá de indicadores de productividad y factores de impacto de las publicaciones de una comunidad académica, algo que contribuye a su formación y consolidación es el reconocimiento de sus héroes. En todo caso, si son realmente académicas, esas comunidades no los tendrán por héroes, sino por referentes intelectuales, más o menos consistentes, más o menos atrevidos y por ello generalmente originales, de los cuales aprender y, también, aprender a distanciarse.

Pedro Morandé pertenece a una generación de la sociología chilena - entre quienes también se cuentan Jorge Larraín, Julieta Kirkwood, Tomás Moulian, José Joaquín Brunner, entre otros- que en las décadas finales del siglo $\mathrm{XX}$ tuvo que construir el futuro de la disciplina. Y tuvo que hacerlo a pesar de la dictadura, y, luego, a pesar de la precariedad institucional. Para ello había que ser consistente, atrevido y original. Si el futuro que esa generación imaginó es el que hoy tenemos, ya no dependía de ella, sino de los que vinimos después. Esto sólo puede decepcionar. Les quedará el consuelo de saber que los de hoy, más temprano que tarde, experimentaremos lo mismo.

El libro Pedro Morandé. Textos sociológicos escogidos, compilado y editado por Andrés Biehl y Patricio Velasco (2017, en adelante citado tan sólo con el número de página), tiene el primer mérito de reponer la

Aldo Mascareño. Sociólogo y antropólogo. Doctor en sociología por la Universidad de Bielefeld. Investigador del Centro de Estudios Públicos y profesor de la Universidad Adolfo Ibáñez. Email: amascareno@cepchile.cl. 
figura intelectual de Pedro Morandé. En todo caso, no estaba olvidado. Su libro Cultura y modernización en América Latina (1984) es un clásico de la sociología latinoamericana; referencia ineludible para cualquiera que quiera investigar el pensamiento regional. Pero el esfuerzo de ordenamiento de Biehl y Velasco nos permite ver también cómo el mismo autor aprende y, en sentidos distintos, bifurca su obra hacia nuevos territorios. La sociología chilena (y la sociología en general) sólo puede agradecer esfuerzos de este tipo, pues con ello promueve la reflexión, se abre a la crítica y madura.

En este artículo quiero revisar el pensamiento sociológico de Pedro Morandé expuesto en la selección de artículos de este libro. Me centraré en tres ámbitos generales de discusión: el barroco iberoamericano, las bases antropológicas y la adopción de la teoría de sistemas. Para cada uno de ellos, elaboro las hipótesis que formulo a continuación.

La primera es que la tesis de la identidad latinoamericana como producto del encuentro entre culturas diversas en la etapa temprana de colonización, y que origina lo que Morandé llama el barroco iberoamericano, tiene el valor de rescatar una época histórica que no ha sido observada ni analizada sociológicamente. Sin embargo, al considerar la síntesis cultural ahí producida como fundante del ser iberoamericano, el autor subvalora la contingencia de la formación de cualquier identidad y hace que las construcciones semánticas posteriores queden degradadas al estatus de fuga del tema central.

La segunda hipótesis es que la formulación de una antropología cristiana construye un tipo de ser humano que es antagónico a la sociedad moderna, por lo que - en la argumentación de Morandé- escenarios como la fiesta, la familia, la religiosidad popular se erigen como reductos de humanidad que dejarían al resto de la sociedad moderna sin un correlato humano que la sustente.

La tercera hipótesis es que el giro a la teoría de sistemas de Niklas Luhmann le permite a Morandé una descripción exhaustiva de la sociedad moderna, pero esta teoría viene también con exigencias postfundacionales que no aceptan demasiada densidad antropológica en la comprensión de lo humano.

Con estas tres hipótesis no aseguro tratar todos los aspectos contenidos en el libro, aunque sí me acerco a reconocer sus contornos. Para desplegar estos argumentos, parto reconstruyendo la explicación 
del barroco iberoamericano entregada por Morandé contenida en la primera parte del libro y la complemento marginalmente con elementos de Cultura y modernización en América Latina (1). Luego, ofrezco una evaluación crítica de esta perspectiva desde un punto de vista de sociología histórica (2), para entonces extraer la antropología cristiana que se despliega especialmente entre la segunda y la cuarta parte del libro y ponerla en relación con otros intentos de vincular antropología cristiana y sociología (3). Continúo entonces con la quinta parte del libro desde lo que denomino el giro sistémico en la evolución intelectual de Pedro Morandé (4). Finalmente, elaboro algunas conclusiones de lo planteado (5).

\section{EL BARROCO IBEROAMERICANO: LA CONSTRUCCIÓN DE UNA CATEGORÍA}

El primer capítulo del libro, en el que se construye la crítica a las teorías sociológicas de la modernización, prepara el escenario para la introducción de la categoría del barroco iberoamericano. La tesis principal aquí es que la apropiación que la academia norteamericana hace de Weber a mediados del siglo XX, especialmente de sus categorías de acción (racional con arreglo a fines, a valores, afectiva y tradicional), termina por esquematizar su teoría en forma de estadios universales de desarrollo en los que la racionalidad técnica se instituye en el pináculo del progreso y la civilización, y Norteamérica, en el arquetipo de ello. Con esto se da la espalda a la historia y a la especificidad cultural de la región: "La sociología criolla renuncia a cualquier tipo de elaboración intelectual propia para concentrarse más bien en torno a los problemas de aplicación del modelo" (44). El problema sociológico pasa a ser la modernización y el método debe ser ahora científico. El pasado disciplinar ya no se define como pensamiento sociológico, sino como ensayismo.

En el ensayismo de inicios del siglo XX, Morandé reconoce un intento genuino de hacerse cargo del vínculo entre modernización y cultura. No es que estos autores (Vasconcelos es el ejemplo de Morandé, pero se podría agregar a Carpentier, Gilberto Freyre, Alcides Arguedas, incluso José Carlos Mariátegui) desconocieran los cambios que se producían en América (industrialización, pobreza, marginalidad) y que dieron origen a la cuestión social de inicios del siglo XX. El problema 
es más bien que el discurso de la identidad había quedado oculto por el liberalismo en el siglo XIX, después por el desarrollismo cepalino del siglo XX, la sociología científica de Germani, el marxismo de la "sociología comprometida" y el giro posterior al mercado como institución general. Contrariamente, Morandé sostiene: "Ninguna institución, como tampoco ninguna conceptualización científica sobre la realidad social, puede lograr vigencia duradera si no interpreta cabalmente la tradición cultural que constituye a los pueblos y sociedades latinoamericanas" (63).

Más allá de que desde Popper (2005) la ciencia se define en oposición a cualquier "vigencia duradera" (provisionalidad del conocimiento por medio de falsación), Morandé logra construir un espacio conceptual para introducir de manera fuerte la preocupación por la identidad cultural latinoamericana y para apoyarse en un pasado ilustre (el ensayismo identitario). La estrategia consiste en oponer la interrogante por la identidad a su subordinación como "tradición", como "obstáculo al desarrollo", como "falsa conciencia" o como "irracionalidad de la acción económica" que los otros paradigmas sociológicos latinoamericanos sostendrían. Ésa es la motivación desde la cual emerge la categoría del barroco iberoamericano.

Luego de dar algunas luces en el capítulo 2 de la primera parte, anticipando fórmulas como "síntesis cultural originaria", "ocultamiento del mestizo", "sustrato católico", el capítulo 3 se dedica directamente a la construcción de la categoría. Ante todo, el barroco iberoamericano designa una época histórica. Morandé la identifica con "la historia de la primera evangelización de América" (81), esto es, siglos XVI y XVII. Sostiene el autor que las comprensiones más extendidas del barroco se remiten a un estilo artístico europeo y a las políticas de la Contrarreforma. Sin desconocer estos significados, Morandé entiende la categoría como descripción de época. Se trata de la formación de "una época histórico-cultural en sus aspectos simbólico-expresivos, simbólico-prácticos, éticos y organizacionales" (83). En ella se produjo el "encuentro" entre pueblos y culturas distintas, no sólo de indígenas e ibéricos, sino también entre pueblos indígenas que previamente no se conocían. En mi perspectiva, la categoría de "encuentro" parece ser insuficiente cuando el período histórico se define con mayor precisión sociológica: "El proceso que analizamos no fue sólo de carácter epistemológico, 
sino un acontecimiento histórico que incluyó dominio político, tributo sobre la población, rearticulación de las economías, introducción de nuevos procesos tecnológicos, educación laboral, evangelización y mestizaje" (84). Generalmente, a procesos de este tipo se los denomina ocupación, conquista, colonización. Pero el concepto de "encuentro" es necesario para elevar la tesis de la "síntesis cultural barroca" a un nivel de mayor abstracción que el permitido por categorías como conquista o colonización.

Acontece que el concepto de barroco iberoamericano tiene que sostenerse en alguna posibilidad de horizontalidad para que efectivamente exista síntesis, a pesar del propio carácter asimétrico de un "encuentro" de este tipo, tal como el mismo Morandé lo reconoce (83 y siguientes). En esa horizontalidad, cada parte debe aportar algo para construir la síntesis. ¿Qué aportaron entonces? Un primer rasgo del barroco iberoamericano es su carácter ecuménico. El lado europeo aporta la experiencia de exploración del mundo; el lado indígena contribuye con la unidad de sociedad y cosmos. La síntesis barroca constituye una cosmovisión en la que "cabían todos los pueblos y todas las particularidades del entorno natural" (96). Un segundo rasgo del barroco es la integración de oralidad y escritura. Los europeos aportaron el lenguaje y su teoría gramática; por el lado indígena se aportó la tradición cúltica y ritual. La síntesis barroca se ejecutó en la Iglesia por medio del rito, el que para cada parte se practicaba de manera eficaz, aunque tuviera significados distintos. Una función similar cumplió la fiesta barroca como síntesis de oralidad no reflexiva indígena y celebración de la cultura escrita cristiana (130-131). Un tercer rasgo es la experiencia del mestizaje y su sacrificio. El mestizo es en sí mismo síntesis, "una presencia en que convergen todas las etnias y todos los grupos sociales" (101). En clave levistraussiana del intercambio de mujeres, en el capítulo 2 ya se nos había dicho que los europeos aportan los hombres y los indios, las mujeres. Ésta es una excepción a la experiencia de "encuentro", pues la mujer "no buscó el encuentro, sino que lo padeció" (73). Sin embargo, para padecerlo se refugió en el ritual (el segundo rasgo). El resultado es el mestizo, aceptado como síntesis barroca por culturas indígenas sin cosmovisión jerarquizada del universo y por misioneros que lo observan como puente entre culturas. Sin embargo, la lectura indigenista y la europeísta lo sacrifican por no pertenecer a una tradición: lo vuelven 
anomalía o intentan blanquearlo como criollo, y, con ello, "se abandona también el fundamento de la identidad" (103).

Por ahora, más allá de cualquier discusión, me parece que Morandé diseña un objeto sociológico para formular preguntas a un período que la sociología regional moderna hasta entonces no había considerado siquiera digno de observación, el de los primeros siglos de la colonización en América. Paralelamente, formula un programa de investigación empírica, pues si se piensa que el barroco iberoamericano constituye una síntesis cultural fundante que encuentra en el mestizo, en la religiosidad popular y en la fiesta formas privilegiadas de expresión, es posible pensar que ese "ethos tiene que expresarse también (...) en todos los planos del acontecer social: en las relaciones cotidianas cara a cara, en la familia, en el trabajo y la economía, en el orden político, en las expresiones artísticas, en la convención sobre los 'buenos modales', etc." (168). El conjunto de capítulos del libro nos muestra claramente que el propio Morandé siguió este programa, y no sólo en los capítulos de la primera parte, sino que también a lo largo de todo el libro: en sus reflexiones sobre la educación, el medio ambiente, la familia y la secularización. Sabemos además que esto creó una escuela sociológica, la del Instituto de Sociología de la Universidad Católica de Chile, con importantes libros como Razón y ofrenda, de Carlos Cousiño (1990), y Politización y monetarización en América Latina, de Carlos Cousiño y Eduardo Valenzuela (2011).

Es decir, hay varias pruebas de la consistencia, atrevimiento y originalidad de los esfuerzos intelectuales de Pedro Morandé. Incluso, afirmaría que la propia sociología de Morandé es una expresión de la síntesis barroca: prefirió la oralidad de las clases y conferencias para la transmisión de su conocimiento antes que los cuatro o cinco libros que la tradición escrita podría esperar de un intelectual de su talla, y basó esa oralidad en las fuentes escritas de la sociología global como también en las no menos sagradas escrituras del catolicismo del siglo $\mathrm{XX}$, como se ve especialmente en las secciones finales de varios de sus artículos. Finalmente, lo que han hecho Biehl y Velasco al publicar este libro es operar el triunfo de la escritura sociológica sobre la preferencia por la oralidad de Morandé. Esto mismo puede ser un ejemplo de que las identidades son más contingentes y paradójicas de lo que estamos dispuestos a aceptar. 


\section{LA CONTINGENCIA DEL BARROCO IBEROAMERICANO}

Como lo he sostenido, valoro que mediante la categoría de barroco iberoamericano se pueda hacer un llamado a la sociología contemporánea a interesarse en las transiciones evolutivas que condujeron al presente. Sobre esto hay en la actualidad opciones teórico-metodológicas interesantes. Probablemente, la más conocida entre las ofertas contemporáneas sea la de Koselleck (2004), quien mediante el concepto de Sattelzeit investiga las transformaciones semánticas que sustentan las prácticas políticas que dan origen a la modernidad europea entre 1750 y 1850-70. Pombeni (2016), por su parte, intenta identificar mediante el concepto de transición histórica los mecanismos evolutivos que operan en el tránsito que va entre el declive de un tipo de organización social y los desafíos que se enfrentan en un determinado presente. En un nivel similar, Sewell (2005) habla de secuencias de ruptura que se entrelazan y dan lugar a eventos históricos transformativos que alteran las condiciones estructurales de una sociedad y la hacen transitar a nuevas articulaciones de sus elementos. Igualmente, la teoría de transiciones críticas ha desarrollado múltiples instrumentos conceptuales y técnicos para el análisis del colapso de sociedades complejas y del modo cómo determinadas estructuras y construcciones semánticas reorientan sus dinámicas para adquirir formas de operación e identidades distintas (Tainter 2017; Yoffee y Cowgill 2003; Schwartz y Nichols 2010; Scheffer 2016; Faulseit 2016).

Precisamente porque se trata de transiciones, ninguna de estas aproximaciones concordaría con el aspecto fundacional de la categoría de barroco iberoamericano que Morandé formula al modo de un template identitario, cuya expresión puede siempre aparecer transfigurada en distintos momentos del tiempo y el espacio. En este sentido, Morandé es más cercano metodológicamente a autores como Spengler o Toynbee que a las modernas teorías de las transiciones históricas. La expresión que Morandé emplea para indicar este template tiene impronta heideggeriana: es la de "morada espacio-temporal compartida" (114). Pero no es la del lenguaje ni la mutabilidad del significado, sino la del "sustrato católico". De esa morada, no es posible escapar. Puede existir una transición al barroco - tal como Morandé la construye con plausibilidad-, pero, al situarla como identidad última, no habría transición desde el barroco; puesto que es originario y fundante, su estructura debiera permanecer. 
Esto llevó a Jorge Larraín (2004) a calificar de esencialista la propuesta de la identidad barroca en un recordado debate durante los años noventa. Podemos ver aquí la respuesta de Morandé:

Difícil resulta comprender que se le pueda imputar a una cultura de la imagen "esencialismo" alguno, si por constitución ella es analógica, es decir, abierta una y otra vez a la reinterpretación y a la reproposición de la originalidad de los mismos símbolos. Mucho más proclive a una imputación de este tipo resulta la cultura estructurada por el concepto, puesto que el "esencialismo" requiere definiciones que el concepto puede aprisionar y no así el símbolo. (114)

Me parece que después de Luhmann $(2005 ; 2012)$ es difícil aceptar que las identidades puedan ser estables, pues subyace a ellas la contingencia de un mundo que no tiene a Dios como contraparte y que opera sólo transitando entre lo posible y lo actual. Esto tampoco significa que no se puedan desarrollar identidades; sólo implica que ellas se forman en la reiteración de operaciones que se concatenan y que logran vencer su propia improbabilidad históricamente hasta que la probabilidad de otras identidades, también históricamente formadas, las desplaza de su centralidad. Un mecanismo de este tipo ha dado origen al barroco iberoamericano, y ese mismo mecanismo produjo nuevas identidades competitivas e igualmente contingentes que hacen perder vigencia y generalización a la identidad barroca. Entenderlo de otro modo conduciría a una conflación de historia e identidad, de práctica y ritual. Sería necesario presuponer plena cohesión y ausencia de inconsistencia en el sistema cultural para trazar una línea segura entre sustrato y reinterpretación (Archer 1997). Las reinterpretaciones por cierto cambian, pero así lo hacen también los sustratos, por ello la propia categoría de "sustrato" presupone más de lo que puede garantizar. Lo mismo acontece con los conceptos. Después de Koselleck (2010), al menos hay que poner en duda que ellos aprisionen significados. Ciertamente se deben presuponer continuidades para apreciar el cambio, pero lo propio de los conceptos es que experimentan transiciones de sentido en relación con las experiencias históricas que significan, y esto es tan central para quienes experimentan como para la sociología que conceptualiza esa experiencia (Luhmann 1998a; Cordero 2017). 
Mi punto con todo esto es el efecto en la interpretación sociohistórica. Concuerdo en varios sentidos con que es necesaria una lectura histórica del barroco iberoamericano. Me parece central para la sociología contemporánea analizar este momento porque muy rápidamente se identifica modernidad con estado-nación e ilustración. Y, en realidad, la formación de la sociedad moderna en América comenzó bastante antes que eso. Desde el punto de vista sociohistórico de la teoría de sistemas (Luhmann 2012), este período que Morandé denomina barroco iberoamericano se caracteriza por la relación entre dos formaciones sociales con principios de organización similares: la europea y la existente en América. Ambas combinan formas de estratificación, de centro-periferia y de segmentación que son funcionalmente equivalentes. El corporativismo monárquico ibérico del siglo XV se ordenaba en centros políticos, jurídicos y comerciales, que replicaban la estratificación de la época, y periferias organizadas en municipios que reflejaban la estructura jerárquica de los centros y construían redes de cooperación hacia abajo. Las sociedades indígenas tenían formas de organización similares: concentración en centros políticos, religiosos y jurídicos con una estratificación desarrollada, y periferias en las que primaba una segmentación generalmente subordinada a los centros. Es decir, lo propio de la sociedad moderna, la diferenciación funcional, simplemente no llega con los españoles. Se comienza a desarrollar en América a través de relaciones comerciales, jurídicas, religiosas y políticas con y dentro de las colonias. La escolástica española e iberoamericana (Vitoria, Mercado, Mariana, Molina, Azpilcueta, entre otros), que Morandé no cita, es justamente una reflexión sobre los orígenes de este proceso. América se transforma en escenario del proceso de construcción de sistemas sociales en el marco de una historia transregional que siglos después daría origen a los estados nacionales, al mercado, a relaciones jurídicas inter y transnacionales, a la ciencia y la educación como espacios autónomos e interdependientes. Un breve pasaje al final del libro da algunas luces sobre el despliegue de diferenciación funcional en América Latina según Morandé (353-355), pero lo que se identifica ahí son hitos de generalización del sistema más que el proceso que los constituye. En tanto, el capítulo sobre la universidad en América (147-165) entrega interesantes lineamientos para analizar el desarrollo histórico del sistema educativo en América (la disputa entre el modelo de Salamanca y el de 
Alcalá de Henares, por ejemplo). No se puede enfatizar poco la relevancia de este tema en la actualidad del sistema universitario y educativo chileno.

El problema no es, por tanto, la historia sociológica del barroco iberoamericano, sino la necesidad, más antropológico-filosófica que sociológica, de reencontrar el barroco en distintas esquinas. Y más importante aún, al considerarlo originario y fundante, las relaciones sociales y las nuevas formaciones de identidad que se desarrollan paralela o posteriormente adquieren un carácter secundario, de ocultamiento del origen, y no son entendidas de manera inmanente al proceso sociológico que las hace emerger. El liberalismo del siglo XIX americano no es un error de la historia ni un trasplante europeo; tampoco lo es la formación de las repúblicas ni el desarrollismo del siglo XX. En todos estos casos hay largos procesos de incubación, ensayo e hibridación que dan forma a las prácticas sociopolíticas regionales y las constituyen en una trayectoria de la modernidad y de la diferenciación funcional. En cada situación se crean nuevas identidades que disputan su lugar con las existentes y que ofrecen formas de inclusión alternativas. Todas tuvieron que imponerse frente a su propia improbabilidad histórica. El liberalismo americano ofreció autonomía individual frente al poder eclesial e igualdad ante la ley frente al poder del Estado (Forment 2003; Ossa 2017); la república ofreció un sentido de autonomía frente a la crisis imperial, puso a disposición también procedimientos de representación política y una perspectiva de soberanía e igualdad como pueblo (Sábato 2018), e incluso el desarrollismo contribuyó a la generalización de una idea de bienestar que aún subsiste como desarrollo humano. Por ello, cuando el barroco iberoamericano pierde presencia frente al liberalismo y la república, o cuando pierde presencia frente al mercado, el Estado y la autonomía sistémica, es equívoco leer a todas estas semánticas e instituciones como ocultamiento del origen. El escenario moderno es de incremento de complejidad e interpenetración; no de autenticidad. En 1491 las culturas indígenas no necesitaban de los españoles en su futuro, pero al año siguiente ahí estaban. El barroco no necesitaba del liberalismo ni de la república, pero la sociedad también tiene su misterio, sociológicamente conocido como contingencia. 


\section{LA ANTROPOLOGÍA CRISTIANA COMO REDUCTO DE HUMANIDAD}

En el "Prólogo" del libro, Eduardo Valenzuela $(2017,31)$ anuncia que las claves hermenéuticas de Pedro Morandé "están referidas - aunque pueden ser apreciadas independientemente de esto- a su condición de creyente". En un mundo plural, escribir desde la condición de creyente no me parece problemático en sí mismo. Para aplicar la lógica morandeana: si el sentido ecuménico del barroco subsiste en forma de pluralismo, entonces el catolicismo también debe tener cabida. La única condición es que se esté dispuesto a observar y a ser observado, como dice Morandé (143). Sin embargo, creo que apreciar las contribuciones de Morandé independientemente de su condición de creyente lleva a separar el argumento antropológico de la descripción sociológica que despliega. Me parece que una de las contribuciones más originales de Morandé en este libro es vincular antropología y sociología especialmente en los capítulos referidos al análisis de la educación (segunda parte), el desafío ecológico (tercera parte) y la familia (cuarta parte). Separar antropología y sociología en el argumento de estos capítulos sería dividir la unidad; y aquí al menos, no quiero jugar el papel del demonio.

En estas reflexiones, la antropología cristiana de Morandé se revela en citas a los Papas, encíclicas, la Biblia y otras fuentes religiosas como una arquitectura fundamental con la cual evaluar el despliegue de la sociedad moderna (al menos en los temas referidos). Algunas de las claves que Morandé entrega para identificar su posición son las siguientes:

a) En la sociedad global, el ser humano "se define esencialmente por su capacidad de observar y ser observado" (143).

b) La persona es síntesis "entre la particularidad de la experiencia contingente de cada sujeto y la universalidad del origen y del destino humano" (148).

c) El ser humano es un "misterio para sí mismo (...) que no puede alcanzar por sí solo la respuesta a la pregunta por el por qué” (173).

d) Los seres humanos se constituyen en la experiencia de gratuidad e igual dignidad "porque reciben la vida como un don de otros y su vocación es entregarla también a otros" (213).

e) Cada ser humano "es portador de la trascendencia del ser presente (...) de modo que la persona tiene (...) una radical indisponibili- 
dad' que la muestra como un fin en sí misma, irreductible a la condición de medio para otros" (237).

f) Para cada ser humano "la extrema fragilidad y contingencia de su origen es, al mismo tiempo, la mayor garantía de su insustituibilidad" (247).

g) El ser humano "es esencialmente un ser-en-relación" (257).

Mientras que en los años ochenta y parte de los noventa la posición de fundamento en la construcción argumental de los escritos de Morandé la ocupa el barroco iberoamericano como síntesis cultural, desde los años noventa en adelante esa posición es ocupada por la persona, o sus iteraciones: ser humano, hombre, presencia. En todo caso, no hay contradicción alguna. Una fórmula de Juan Pablo II le sirve a Morandé para unir cultura y ser humano: el ser humano es el "único sujeto óntico de la cultura" (181). En palabras de Wojtyla (1980): "El hombre, que en el mundo visible, es el único sujeto óntico de la cultura, es también su único objeto y su término. La cultura es aquello a través de lo cual el hombre, en cuanto hombre, se hace más hombre, es más, accede más al ser". Este hacerse más hombre del hombre no se alcanza en soledad (eso sería individualismo), sino en tanto el hombre acepta que es un misterio para sí mismo, lo que únicamente acontece frente a otro misterio. Como señala Morandé: "Tal comprensión solo puede darse en relación a un misterio más grande, al misterio de Dios (...) Pero comprender simultáneamente el misterio de Dios y el misterio del hombre solo puede hacerse desde la revelación que Dios hace de sí mismo como hombre" (173). "Comprender el misterio" es una fórmula paradójica, pero lo bueno de las paradojas es que no requieren explicación, sino despliegue. No hay que preocuparse por resolverlas, porque son la marca de una incompletitud que ellas mismas anuncian y suplementan a la vez. Por esto, más vale observar qué es lo que se produce alrededor de ellas, esto es, la sociología como suplemento subversivo del fundamento, para decirlo derridianamente.

Mi punto es que al situar los argumentos en relación directa con fuentes religiosas, la relación entre antropología y sociología se vuelve antagónica, y la antropología de Morandé se presenta como un núcleo categorial que es constantemente negado por la construcción de la sociedad moderna. En los artículos sobre la educación (segunda parte), la cuestión ecológica (tercera parte) y la familia (cuarta parte), se aprecia 
claramente este antagonismo entre fundamento antropológico y sociedad moderna. A la segunda parte subyace la preocupación por el olvido de la síntesis cultural barroca en la construcción de la universidad (159 y siguientes) y el oscurecimiento de la tradición sapiencial producida por la tecnificación del sistema universitario actual (175 y siguientes, 184 y siguientes). Los capítulos de la tercera parte continúan auscultando este antagonismo: sostienen que la ética kantiana y la de valores han eclipsado una ética de la gratuidad que puede hacer frente al desafío ecológico (197 y siguientes); que el nihilismo moderno ha separado antropología y cosmos transformando la naturaleza en medioambiente (201 y siguientes) y que la neutralidad valórica moderna renuncia a una concepción de justicia basada en una determinada comprensión de persona y de sociedad (210). Los capítulos de la cuarta parte, en tanto, reafirman este antagonismo: argumentan que la sociedad tecnológica ha intentado pero no ha logrado sustituir la conciencia de filiación en la familia ni la percepción de la vida como don (221); que las dificultades actuales en el reconocimiento de la paternidad humana en la familia son obra del racional-iluminismo (251); que la autonomía individual moderna desconoce la dependencia filial acontecida en la familia (257), empobreciendo con ello la visión general sobre la realidad humana (273). Por supuesto no desconozco que la fiesta (125 y siguientes), la religiosidad popular (354), la comunidad de maestros y discípulos (186), la familia como communio personarum (257), son espacios donde Morandé ve que se concretiza la antropología propuesta. Pero el énfasis en las oposiciones de esa antropología en relación al despliegue de la sociedad moderna hace que estas manifestaciones queden situadas como reductos exclusivos de la humanidad, con lo que pareciera no haber ser humano que sostenga todas las otras manifestaciones de la sociedad en que vivimos.

Con esto, creo, se pierde la pregunta por el tipo de ser humano que está tras la dinámica de diferenciación y fragmentación de la sociedad moderna. Otras sociólogas y sociólogos — también miembros de la Academia Pontificia - han intentado aproximarse a esta pregunta por medio de una reconstrucción de los conceptos de persona y relación. Margaret Archer, por ejemplo, después de desarrollar su teoría sociológica del enfoque morfogenético como un dualismo analítico que observa el juego mutuo entre estructuración e interacción social en el tiempo 
para explicar lo social, sostiene que las posiciones sociales de actor y agente son "apadrinadas" por la persona "tanto filo como ontogenéticamente" (Archer 2009, 341). Existen propiedades de las personas que operan como condiciones de posibilidad de lo social (condiciones de borde se diría sistémicamente) y que mantienen eficacia causal sobre ella. Éstas son: la continuidad de la conciencia, la continuidad corporal y la relación no social con entidades no sociales (naturaleza y trascendencia). No es el caso hacerse aquí las preguntas correspondientes sobre Archer; lo interesante es que se manifiesta una antropología que retorna más a la naturaleza que a alguna entidad supraorgánica (incluida la sociedad).

Pierpaolo Donati sigue líneas similares, esta vez con otra condición de posibilidad del reconocimiento de personas, su carácter relacional. La persona está en tensión con el mundo biofísico y la trascendencia. Siendo singular y concreto "el individuo tiene una identidad personal y una social. La primera es presocial y metasocial, mientras que la segunda es formada en relaciones con otros y con el mundo social en general" (Donati 2011, 49). De más está decir que el carácter relacional de los fenómenos sociales y de la constitución de las personas están en la base de varios conceptos de Morandé. No es posible comprender cabalmente categorías como encuentro, don, reciprocidad, comunidad, reconocimiento, sin el recurso a la relacionalidad. Morandé lo introduce a propósito de Juan Pablo II (257) y Benedicto XVI (274), pero analíticamente circunscribe esa relacionalidad a la familia. Hay también mención a algunas fuentes como Mauss, Zubiri y Heidegger en estas argumentaciones, pero son más bien los Papas los que dominan la escena antropológica y argumental.

Ampliando el espectro antropológico, la posibilidad de conectar antropología y sociología podría no sólo remitirse a la oposición entre ser humano y sociedad, sino también a esclarecer el tipo de ser humano que la sociedad ha requerido (o ha producido) para comportarse hoy del modo en que lo hace. Es decir, no es sólo un problema de fuentes filosóficas para la descripción del ser humano, sino de cómo esa descripción se hace compatible con la sociedad que tenemos y la esclarece en algún sentido. De otro modo, la humanidad queda solamente confinada a reductos: fiesta, religiosidad popular, conocimiento sapiencial, relación aprendiz-maestro, matrimonio, familia. Lo demás — diferen- 
ciación, técnica, fragmentación, complejización, procedimiento- no sabemos de qué "hombre" viene, pero habría que concluir que no tiene vinculación con lo humano.

Acontece que la inquietud antropológica no es solamente una preocupación de la religión. Sin ir más lejos, la de Archer es lockeana y kantiana (ver Archer 2009, 374 y siguientes), lo que podría parecer demasiado liberal para la perspectiva de Morandé. Incluso pragmatistas y "neoiluministas" han debatido desde hace algún tiempo sobre la interpenetración de antropología y sociología (Honneth y Joas 1988; Morgan 2016; Chernilo 2017). En un sentido histórico, para Odo Marquard (2007), la antropología filosófica ha mantenido desde su origen un giro al mundo de la vida y a la naturaleza que se inicia, en sentido estricto, con Kant, cuando la crítica a la razón deja en claro que ni la metafísica ni la matemática ofrecían una teoría de la vida cotidiana. Sin embargo, en Kant la antropología queda subordinada al proyecto de filosofía de la historia cosmopolita, que enfatiza lo que el ser humano hace o debe hacer para ser libre. El romanticismo del idealismo alemán es una reacción a esto. Para liberarse de la opresión del progreso histórico se gira la mirada a la naturaleza del ser humano: qué hace la naturaleza con el ser humano, pasa a ser la pregunta central. Hegel reapropia la antropología para la filosofía de la historia criticando al romanticismo por la insuficiencia del espíritu natural para afrontar la historia; "antropología" ya no es lo que el ser humano debe, sino lo que puede. Mientras que Dilthey la hace retornar a la naturaleza como aquello que se mantiene en el ser humano a pesar de la historia. Heidegger igualmente crítica a la antropología filosófica cuando se pone al servicio de la filosofía de la historia y subordina a ella el mundo de la vida. Löwith, Scheler y Gehlen, en tanto, sostienen el retorno a la naturaleza como núcleo de la antropología contemporánea, lo que en general comparte la antropología como disciplina científica.

Concluye Marquard (2007) que en tanto la oposición entre antropología filosófica y filosofía de la historia se busque eliminar, las constantes naturales del ser humano se mantienen, pero se indaga en el modo en que la sociedad las transforma. El utopismo de la filosofía de la historia queda así reducido a posibilidades (como en la dialéctica negativa de Adorno o en la razón como mito entre mitos en Lévi-Strauss). Si en cambio la filosofía de la historia es entendida en oposición radical 
a la antropología filosófica, esta última se convierte en guardiana del pluralismo, pues se elimina el peso de la finalidad histórica sobre un presente culturalmente diverso. Según Marquard, Gadamer sería quien con mayor precisión representa esta posición: "El título de antropología refuerza allí no sólo la libertad del hombre para ser aquello que le constituye cada uno a su manera, sino también la libertad de las diversas ciencias para expresarse, cada una a su manera, sobre el ser humano" (Marquard 2007, 151).

¿Cuál es la posición de la antropología cristiana de Morandé en este escenario? Sin duda no es la de la filosofía de la historia. Una constante del libro es la crítica a la tradición iluminista - tributaria de la filosofía de la historia - que ha olvidado, u ocultado incluso, el fundamento antropológico y cultural (aunque la idea de ser humano como fin en sí mismo que Morandé sostiene tiene, al menos, resonancias kantianas). Pero tampoco parece ser que Morandé saque consecuencias pluralistas de su renuncia a la utopía iluminista. Si así fuera, habría que asumir la diversidad de formas de familia, o las varias justificaciones del rol de la educación, o las distintas concepciones de ser humano en las ciencias, o de persona en los sistemas funcionales (Luhmann 1998b). Y teniendo esto en consideración, habría que hacerse la pregunta radical por el tipo de ser humano que es compatible con esta sociedad. De ese modo, antropología y sociología adquirirían una integración productiva y no sólo antagónica, con lo que se podría considerar a la sociedad moderna como horizonte de posibilidades más que como un mundo dominado por el nihilismo (135, 172, 201, 254, 274 y 328). Me parece que el acercamiento de Morandé a la sociología de Niklas Luhmann puede llegar a ofrecer esta alternativa.

\section{EL GIRO SISTÉMICO}

Si hay una teoría sociológica actual que haya calado hondo en las reflexiones de Pedro Morandé es la de Niklas Luhmann: "el gran sociólogo alemán de esta época" $(172,184)$; "uno de los más destacados sociólogos de nuestro tiempo" (258); "el único sociólogo que ha buscado abrir el cauce a una explicación diferente" (343). Hay varias razones para esta adopción: la oposición de Luhmann a la teoría crítica de Habermas — una forma avanzada de neoiluminismo-; la disolución de 
una racionalidad universal en operaciones de sistemas funcionalmente diferenciados; la desocialización del ser humano al situarlo fuera de la sociedad; la interpenetración de conciencia y comunicación por medio del lenguaje; la lectura husserliana que Luhmann hace de la conciencia como autopoiesis de la intencionalidad; la concepción de intimidad de Luhmann como espacio de reconocimiento de la unidad del individuo. Morandé recurre a estas formulaciones desde la década de 1990 en adelante. Hay, sin embargo, otras dos operaciones teóricas en Luhmann que quisiera destacar y que me permiten hablar especialmente de la última sección del libro. Éstas son la figura del tercero excluido y la reducción de complejidad.

Incluso más que los originales artículos sobre la modernidad en América, el capítulo sobre el sacrificio en la polis (289-316) me parece un ejemplo de las alturas a las que puede llegar el ensayo sociológico al combinarse con la reflexión antropológica. Este capítulo data de 1981, un año después de ratificada la Constitución de 1980 y un año antes de la mayor crisis económica de la dictadura. Morandé conecta su motivación sociológica con el espíritu de la época sin eufemismos: "La discusión acerca del concepto de guerra interna y acerca de la vigencia de los derechos humanos fundamentales son síntomas inequívocos de la percepción de la presencia del sacrificio en la vida social de este período" (290). El argumento central se resume en la clara definición de sacrificio: "una acción social específica que hace de la inmolación de la víctima una fuente de creación de valor" (292). La figura del sacrificio ritual es propiamente antropológica, pero simbólicamente la semántica de la época la reproduce en forma de "costo social" o "costo alternativo". Incluso Morandé propone una clave hermenéutica de teoría general: la modernidad puede ser comprendida de acuerdo al modo "en que concibe el sacrificio y su papel en la vida social” (295). Según Morandé, la víctima asume este sacrificio simbólicamente como condición de su rol en la sociedad. Puesto que la diferenciación de funciones requiere legitimación de su operación, ella transforma en ética el cumplimiento de roles y la interdependencia entre sistemas. Morandé parece referir aquí más a Parsons que a Luhmann, a quien en 1981 seguramente no había leído sistemáticamente. No obstante, si la interdependencia y los roles se apoyan en la ética, entonces "todos somos víctimas para todos, dentro de los marcos específicos de cada una de las funciones sociales 
que desempeñamos" (304-5). El sacrificio, entonces, se introyecta. No es un acontecimiento especial que escapa a la "normalidad", sino que acontece a diario: es la exclusión que suplementa la incompletitud del sistema.

El esbozo de teoría del sacrificio en la sociedad moderna que Morandé hizo hace 37 años se puede continuar hoy por medios sistémicos sin mayores sobresaltos. En la teoría de Luhmann, la figura del tercero excluido es cercana a esta comprensión. Ella tiene dos acepciones: a) es el observador que no puede observarse a sí mismo en el momento en que observa (Luhmann 2012); pero también es b) un observador posicionado en el entorno inmediato de la operación, que participa de ella como suplemento. Es un tercero excluido incluido (Luhmann 2017). En esta segunda acepción, el tercero excluido es el equivalente de la víctima sacrificial. Es el, la, lo que se niega para dar continuidad a la operación. Por ejemplo, en el campo económico alguien necesita un bien tanto como otros, pero acepta que otros lo obtengan sólo porque se paga; en la política el mandato es aceptado porque en última instancia un tercero (excluido-incluido) puede ejercer la coerción física; en la historia del siglo XX el trabajo no depone al capital porque el consumo del trabajador pacifica el ánimo de revolución. Morandé aplica su enfoque sacrificial al mestizo - "es la novedad sacrificada del encuentro" (103) — y a los aspectos referidos en el capítulo: la pobreza, el cumplimiento de roles. Sin embargo, combinando teoría de sistemas y sacrificio, distintos temas del libro pueden obtener un giro sistémico. No sólo el conocimiento sapiencial sería la víctima de la universidad moderna (175 y siguientes, 184 y siguientes), también puede serlo la originalidad científica producto de la relación entre productividad académica y multiplicación de funciones. No sólo la concepción de unidad de hombre y cosmos se sacrifica con el problema ambiental (201 y siguientes), los terceros excluidos-incluidos de los requerimientos industriales y energéticos son ahora explícitamente llamados "zonas de sacrificio". No es el reconocimiento de la paternidad humana lo que se sacrifica en la familia moderna (251 y siguientes), más bien es la tercera excluida-incluida la que ha sacrificado su inclusión funcional en favor de la reproducción humana. La integración de sistemas y simbolismo en la perspectiva del sacrificio me parece una tarea sociológica de la más alta relevancia, pues, además de científicamente original, ella permite 
observar múltiples desigualdades e inequidades sociales bajo un prisma distinto.

Los dos capítulos finales discuten la posición de la religión ante la ciencia y la secularización, y vuelven sobre motivos antropológicos combinados con preocupaciones sociológicas. Dice Morandé: "Las relaciones entre ciencia y fe han sido problemáticas allí donde ambas han disputado acerca de los presupuestos antropológicos de su existencia histórica y acerca de los principios de legitimación del orden social que derivan de tales presupuestos antropológicos" (320). Morandé observa en el racional iluminismo y en el neoiluminismo (estructuralismo, positivismo lógico, racionalismo crítico) los principales antagonistas de la fe. Este tipo de pensamiento le niega a la fe la posibilidad de mediar entre ser humano y sociedad por considerarla arcaica, irracional, ideológica. No obstante, en la medida en que la teoría de sistemas supera los presupuestos del neoiluminismo, "se abandona la pretensión monopólica y totalizante de las ciencias sociales" (335) y se deja espacio a la contingencia.

En un sentido similar, el capítulo final recurre al proceso de diferenciación funcional descrito por Luhmann como explicación sociológica del despliegue de la secularización. Ésta no sería estrictamente un desencantamiento del mundo producido por la pérdida de vigencia de las ideas religiosas, sino más bien un efecto de la autonomía de los sistemas sociales que rechazan comunicaciones que no les competen y renuncian a aceptar un punto de vista externo y superior (Dios, Estado, razón universal) desde el cual se direccione la totalidad. La comunicación religiosa queda concentrada en el sistema de la religión y dependerá de los demás sistemas cuánto aceptan de su comunicación. Con esto, sostiene Morandé, "la tesis de una ley natural que resumía todo el sentido de la existencia y que unificaba el misterio de la creación y el misterio de la salvación, empieza a perder sus referencias en la sociedad policontextural que resulta de la diferenciación funcional” (347). Esa "ley natural" - afirma Morandé, en sintonía con el argumento de Marquard (2007) antes expuesto - debe sustentarse ahora en la naturaleza, con lo que se da origen a la antropología filosófica.

Sin embargo, cuando se acepta a Luhmann como descripción de la sociedad moderna, vienen algunas exigencias asociadas. La primera es que la contingencia de la sociedad moderna no tiene como contraparte 
la necesidad de Dios, sino las necesidades que la propia sociedad presenta como ineludibles. La segunda es que la contingencia requiere reducción de complejidad, y la religión es sólo un mecanismo entre otros que pueden aportar a tal reducción. La tercera es que al haber múltiples sistemas que reducen complejidad, la contingencia y necesidad aumentan en términos absolutos; es decir, aumenta la diversidad en la sociedad. Contra esa complejidad se rebelaron los extremismos del siglo XX, como lo ha hecho ver Sloterdijk (2016). Una antropología categorial, que tenga las cosas demasiado claras y que por tanto las formule como necesidad, se verá permanentemente empujada a unir la diferenciación y disolver diversidad. Una antropología negativa de la incompletitud humana está en mejor posición de navegar en la contingente sociedad moderna, soportando la oscilación entre reducción y aumento de complejidad. En esto, Gehlen (1988) aporta distinciones interesantes. Apoyándose en Nietzsche y en oposición a fórmulas metafísicas, define al "hombre" como animal aún no determinado, inacabado, no firmemente establecido y, por ello, abierto al mundo. Marquard (2000) saca de esto consecuencias importantes. La diversidad que la apertura al mundo produce es oportunidad de libertad individual, en todo caso modesta y finita, "pues los seres humanos son libres no al copiar a Dios en tanto que jefes cuasi omnipotentes del orden mundial o mediante una facultad incondicionada; sino que son libres mediante las libertades (en plural) que les caen en suerte cuando los determinantes que se abalanzan sobre ellos para determinarlos se estorban unos a otros" (Marquard 2000, 144-5). En otras tradiciones, a esto se lo denomina libertad negativa.

\section{CONCLUSIÓN}

Los escritos de Pedro Morandé reunidos en el libro editado por Biehl y Velasco son exigentes en varios sentidos. En primer lugar, sociológicamente hablando, pero también histórica y antropológicamente. Por ello, como todo buen libro, abre interrogantes interdisciplinarias y motiva a la investigación teórica y empírica. Me parece, por ejemplo, que es efectivamente urgente una renovación, en términos de sociología histórica, de lo que Morandé llama barroco iberoamericano; es decir, el período entre el siglo XVI y XVII. No porque piense que ahí estén las claves de la identidad latinoamericana, sino, por una parte, porque en 
ese período se produce una transición histórica generalizada entre una forma de organización de la complejidad social y otra que descompone y recombina estructuras, semánticas y dinámicas sociales que debe ser reanalizada a la luz de nuevos instrumentos conceptuales y técnicos. Y, por otra, porque ni la diferenciación funcional, ni la república, ni el ideario moderno o su síntesis pueden ser entendidos como necesidad histórica. Lo que se requiere es mostrar históricamente cómo se sobreponen a su propia improbabilidad, cómo su triunfo nunca es total y cómo siempre hay alternativas que coexisten con las formas predominantes.

En segundo lugar, creo que la sociología empírica puede encontrar múltiples motivaciones de investigación en los capítulos sobre educación, ecología humana y familia. He señalado más atrás la importancia de una historia temprana de la universidad en América. Asimismo, cuando la designación antropoceno se ha popularizado hasta el punto de alcanzar formas de esoterismo estilo west coast, la pregunta por el desafío ecológico debe renovarse como preocupación por la contaminación y la desigualdad. En el libro, Morandé se interroga de este modo por los problemas ecológicos planteando cuestiones éticas y de equidad. También sus estudios sobre la familia abren fuentes de investigación empírica, como las relacionadas con la transmisión de valores o el diálogo intergeneracional, entre otros.

En tercer lugar, decididamente la publicación de este libro incrementa la densidad conceptual del debate sociológico latinoamericano y de sus intersecciones con la antropología, la historia y la filosofía. El esbozo que Morandé hace de una teoría del sacrificio en la sociedad moderna puede ser un punto de contacto para ese diálogo. Incluso la investigación empírica puede apoyarse en esas premisas. También motiva a ese diálogo interdisciplinario la continua preocupación antropológica del autor. La discusión acerca de qué antropología para nuestra sociedad es conceptual tanto como empírica; aunque entiendo que justamente el modo en que esta pregunta se plantea ya forma parte del debate que anuncia.

Finalmente, no quiero dejar de referirme al ensayo como soporte de la argumentación sociológica. En una época en la que muchas veces hay que vaciar la autopoiesis de la conciencia en templates ("Introduction", "Methods", "Results", "Discussion", "Conclusions"), un 
libro como éste resulta refrescante. Atribuiría esto a la originalidad de Morandé más que al género del ensayo sociológico. Sin embargo, hay algo en el soporte que contribuye a refrescar: en el ensayo mandan las transiciones y continuidades del argumento y no las del paper hiperformalizado. Para parafrasear el debate antropológico, el ensayo es un escrito aún no determinado, inacabado, no firmemente establecido y por ello abierto al mundo; puede ocurrir con él lo que ocurra. El paper en cambio es un escrito cuya estructura conocemos por anticipado; sólo hay que ver cómo se ejecuta y luego juzgar cuán lejos resultó de la perfección. Hoy coexisten ambos, pero la gran ventaja del ensayo sobre el paper es que el primero puede también seguir la estructura del segundo, entre varias otras formas plurales que igualmente puede adoptar, tal como lo muestra el libro de Pedro Morandé.

\section{REFERENCIAS}

Archer, M. 1997. Cultura y teoría social. Buenos Aires: Ediciones Nueva Visión.

- 2009. Teoría social realista. El enfoque morfogenético. Santiago: Ediciones Universidad Alberto Hurtado.

Biehl, A. \& P. Velasco, eds. 2017. Pedro Morandé. Textos sociológicos escogidos. Santiago: Ediciones UC.

Chernilo, D. 2017. Debating Humanity. Towards a Philosophical Sociology. Cambridge: Cambridge University Press.

Cordero, D. 2017. Crisis and Critique. On the Fragile Foundations of Social Life. Abingdon: Routledge.

Cousiño, C. 1990. Razón y ofrenda: ensayo en torno a los límites y perspectivas de la sociología en América Latina. Santiago: Cuadernos del Instituto de Sociología, Pontificia Universidad Católica de Chile.

Cousiño, C. \& E. Valenzuela. 2011. Politización y monetarización en América Latina. Santiago: Instituto de Estudios de la Sociedad.

Donati, P. 2011. Relational Sociology. Londres: Routledge.

Faulseit, R. 2016. Beyond Collapse. Archaeological Perspectives on Resilience, Revitalization, and Transformation in Complex Societies. Carbondale: Southern Illinois University Press.

Forment, C. 2003. Democracy in Latin America, 1760-1900. Chicago: The University of Chicago Press.

Gehlen, A. 1988. Man: His Nature and Place in the World. Nueva York: Columbia University Press.

Honneth, A. \& H. Joas. 1988. Social Action and Human Nature. Cambridge: Cambridge University Press. 
Koselleck, R. 2004. "Einleitung”. En Geschichtliche Grundbegriffe, editado por O.

Brunner, W. Conze \& R. Koselleck. Stuttgart: Klett-Cotta.

- 2010. Begriffsgeschichten. Frankfurt: Suhrkamp.

Larraín, J. 2004. Identidad y modernidad en América Latina. México DF: Océano.

Luhmann, N. 1998a. "Gesellschaftliche Struktur und semantische Tradition".

En Gesellschaftsstruktur und Semantik. Studien zur Wissenssoziologie der modernen Gesellschaft. Band I. Frankfurt: Suhrkamp.

1998b. "La forma 'persona”". En Complejidad y modernidad, 231-244. Madrid: Trotta.

—. 2005. "Identität - was oder wie". En Soziologische Aufklärung 5. 15-30. Konstruktivistische Perspektiven. Wiesbaden: VS Verlag.

. 2012. Theory of society. Stanford: Stanford University Press.

2017. La economía de la sociedad. México DF: Herder.

Marquard, O. 2000. Apología de lo contingente. Valencia: Institució Alfons el Magnànim.

-2007. Las dificultades con la filosofía de la historia. Valencia: Pre-Textos.

Morandé, P. 1984. Cultura y modernización en América Latina. Santiago: Instituto de Sociología, Pontificia Universidad Católica de Chile.

Morgan, M. 2016. Pragmatic Humanism: On the Nature an Value of Sociological Knowledge. Londres: Routledge.

Ossa, J. L. 2017. "Revolución y construcción republicana en Chile, 1810-1851". En Historia politica de Chile, 1810-2010. Tomo I: Prácticas políticas, editado por I. Jaksic \& J. L. Ossa, 23-52. México DF: Fondo de Cultura Económica Universidad Adolfo Ibáñez.

Pombeni, P. 2016. The Historiography of Transition. Critical Phases in the Development of Modernity (1494-1973). Abingdon: Routledge.

Popper, K. 2005. The Logic of Scientific Discovery. London: Routledge.

Sábato, H. 2018. Republics of the New World. Princeton: Princeton University Press.

Scheffer, M. 2016. "Anticipating societal collapse; hints from the Stone Age". PNAS 113 (39): 10733-10735.

Schwartz, G. \& J. Nichols, eds. 2010. After Collapse. Tucson: University of Arizona Press.

Sewell, W. 2005. Logics of History. Social Theory and Social Transformation. Chicago: The University of Chicago Press.

Sloterdijk, P. 2016. ¿Qué sucedió en el siglo XX? Madrid: Siruela.

Tainter, J. 2017. The Collapse of Complex Societies. Cambridge: Cambridge University Press.

Valenzuela, E. 2017. "Prólogo". En Pedro Morandé. Textos sociológicos escogidos, editado por A. Biehl \& P. Velasco, 19-32. Santiago: Ediciones UC.

Wojtyla, K. 1980. "Discurso del santo padre Juan Pablo II a la Organización de las Naciones Unidas para la educación, la ciencia y la cultura - UNESCO”. http:// 
w2.vatican.va/content/john-paul-ii/es/speeches/1980/june/documents/hf_jpii_spe_19800602_unesco.html/.

Yoffee, N. \& G. Cowgill, eds. 2003. The Collapse of Ancient States and Civilizations. Tucson: University of Arizona Press. EP 